\title{
ANÁLISE DO PLANO DIRETOR PARTICIPATIVO DE IBIMIRIM, PERNAMBUCO: INEFICIENCIAS E DESAFIOS ${ }^{1}$
}

\author{
ANALYSIS OF THE PARTICIPATORY MASTER PLAN OF IBIMIRIM, PERNAMBUCO: \\ INEFFICIENCIES AND CHALLENGES
}

\author{
ANÁLISIS DEL PLAN MAESTRO PARTICIPATIVO DE IBIMIRIM, PERNAMBUCO: \\ INEFICIENCIAS Y DESAFÍOS
}

Patrício Rinaldo dos Santos ${ }^{2}$
Márcio Catharin Marchetti

\begin{abstract}
Resumo
O crescimento urbano desordenado e sem planejamento tem contribuído para o surgimento de vários problemas socioeconômicos e ambientais, até mesmo em pequenas cidades localizadas no semiárido do Nordeste brasileiro. Objetivou-se com este estudo verificar as ineficiências e os desafios que norteiam a implantação do Plano Diretor Participativo do município de Ibimirim, estado de Pernambuco. O estudo em evidência é de caráter descritivo e exploratório complementando-se, para o alcance dos resultados propostos, com o método observacional. Foram feitas análises documentais e observações diretas em campo. Verificou-se que o Plano Diretor está composto por eixos e que algumas normas não estão sendo cumpridas conforme a legislação em vigor. O município não revisa o seu Plano Diretor desde o ano de 2006 e não existe fiscalização nas construções, devido à ausência de instrumentos, como o código de posturas, o código de obras e edificações e o zoneamento urbano-ambiental. Espera-se que esta observação possa subsidiar políticas públicas para uma regularização urbana e promoção de melhores condições de vida para as presentes e futuras gerações, neste e em outros municípios do semiárido.
\end{abstract}

Palavras-chave: Urbanização. Estatuto das cidades. Plano Diretor. Ibimirim.

\begin{abstract}
The uncontrolled and unplanned urban growth has contributed to the insertion of several socioeconomic and environmental problems, even in small cities located in the semi-arid region of Northeast Brazil. The objective of this study was to verify the inefficiencies and challenges that guide the implementation of the Participatory Master Plan of the municipality of Ibimirim, state of Pernambuco. The study in evidence is descriptive and exploratory, complementing it in the proposed results' scope with the observational method. Documentary analyses and direct observations were made in the field. It was found that the Master Plan is composed of axes and that some standards are not being complied with according to the legislation in force. The municipality has not revised its Master Plan since 2006, and there is no inspection in the buildings due to the absence of instruments, such as the city administrative rules, the code of works and buildings, and the urban-environmental zoning. It is expected that this observation can support public policies for urban regularization and promotion of better living conditions for present and future generations, in this and other municipalities of the semi-arid region.
\end{abstract}

Keywords: Urbanization. Statute of cities. Master plan. Ibimirim.

\section{Resumen}

\footnotetext{
${ }^{1}$ Este artigo apresenta uma síntese do Trabalho de Conclusão de Curso (TCC) intitulado "Ineficiências na implementação do plano diretor participativo de Ibimirim - PE", defendido pelo autor em 2017 no Curso de Pós-Graduação Lato Sensu em Gestão, Licenciamento e Auditoria Ambiental, Campus Araripina - PE, da Universidade Norte do Paraná - UNOPAR, sob orientação do Professor Mestre Márcio Catharin Marchetti.

2 Tecnólogo em Gestão Ambiental. Especialista em Gestão, Licenciamento e Auditoria Ambiental. Mestrando em Desenvolvimento e Meio Ambiente Universidade Federal de Pernambuco (PRODEMA/UFPE). E-mail: patricioibimirim@hotmail.com.

${ }^{3}$ Graduado em Licenciatura e Bacharelado em Geografia. Mestre em Geografia. Universidade Norte do Paraná (UNOPAR). E-mail: mmarchetti2x@gmail.com.
} 
El crecimiento urbano desorganizado y no planificado ha contribuido para la generación de varios problemas socioeconómicos y ambientales, incluso en pequeñas ciudades ubicadas en la región semiárida del noreste de Brasil. El objetivo de este estudio fue verificar las ineficiencias y los desafíos que guían la implantación del Plan Maestro Participativo del municipio de Ibimirim, estado de Pernambuco. El estudio en evidencia es descriptivo y exploratorio, complementado, para lograr los resultados propuestos, por el método de observación. Se realizaron revisiones documentales y observaciones directas de campo. Se encontró que el plan maestro está compuesto por ejes y que algunas normas no se cumplen de acuerdo con la legislación vigente. El municipio no ha revisado su Plan Maestro desde 2006 y no hay inspección en los edificios, debido a la ausencia de instrumentos como las normas administrativas municipales, el código de obras y edificios y la zonificación urbano-ambiental. Se espera que esta observación pueda apoyar las políticas públicas para una regulación urbana y la promoción de mejores condiciones de vida para las generaciones presentes y futuras, en este y en otros municipios de la región semiárida.

Palabras-clave: Urbanización. Estatuto de las ciudades. Plan maestro. Ibimirim.

\section{Introdução}

O uso e a ocupação do espaço, ao longo dos anos, vêm ocorrendo de maneira desordenada e sem levar em consideração a fragilidade dos recursos naturais (FARIAS; SILVA; RODRIGUEZ, 2013). Diante de tais problemas surgem artifícios regulatórios como, por exemplo, os planos diretores que, conforme entendimento de Oliveira, Lopes e Sousa (2018), são os instrumentos de intervenção mais importantes das autoridades públicas. De forma detalhada, eles definem as regras de uso, ocupação e transformação do uso dos solos urbanos e rurais.

De acordo com Mattos e Antoniazzi (2017), o Plano Diretor elabora estratégias e diretrizes com objetivo de desenvolver o espaço físico e territorial do município dentro do prazo pré-determinado. Não é obrigatório estipular tal prazo, porém através do planejamento é possível prever quando será realizado e concluído. Meurier e Vieira (2010) relatam que

No universo de mais de 5.560 municípios brasileiros, a maioria é considerada como município de pequeno porte, com menos de 20.000 habitantes, não sendo necessário, conforme a Constituição da República Federativa do Brasil - CRFB de 1988, a construção de um Plano Diretor nesses casos. O Estatuto da Cidade, Lei Federal $\mathrm{n}^{\circ} 10.257 / 2001$, regulamenta os artigos 182 e 183 da Constituição Federal, que tratam da Política Urbana e estabelecem diretrizes e instrumentos no intuito de orientar e dar suporte aos municípios na construção da política de desenvolvimento urbano local [...] (MEURIER; VIEIRA, 2010, p. 2).

Silva et al. (2013) advertem que cada município possui as suas próprias regras e essas são definidas normalmente no Plano Diretor, na Lei de Uso e Ocupação do Solo e no Código de Obras (ou edificações). Freitas e Bueno (2018) descrevem que,

Os governos não têm sido cobrados pela implementação dos planos porque os processos de discussão fracassaram em envolver a população, não foram reconhecidos pelos atores locais, foram pouco divulgados ou mesmo não se aprofundaram em temas necessários para que um novo pacto territorial fosse efetivado (FREITAS; BUENO, 2018, p. 2). 
Infelizmente, devido à falta de comprometimento do poder público, o instrumento do Plano Diretor contido no Estatuto das Cidades (Lei 10.257/2001), na maioria dos casos, não é levado em consideração no que se refere à promoção de políticas públicas de cunho informativo junto aos habitantes. Encontra-se, na maioria dos casos, incrementado por revisões atrasadas e sem efetivação de ações práticas por parte dos órgãos responsáveis nos municípios brasileiros, sobretudo, nas cidades interioranas.

Além disso, são poucas as pesquisas desenvolvidas que involucram a adoção de paradigmas sustentáveis e a importância da implantação dos planos diretores participativos nas cidades do Semiárido do Nordeste brasileiro. Neste contexto, objetivou-se com este estudo verificar as ineficiências e os desafios que norteiam a implantação do Plano Diretor Participativo do município de Ibimirim, estado de Pernambuco.

\section{Metodologia}

A referida pesquisa foi realizada entre os anos 2016 e 2018 e complementada em 2020, na cidade de Ibimirim, Sertão do estado de Pernambuco, distante $314 \mathrm{~km}$ da capital do estado, Recife. Geograficamente, Ibimirim situa-se na latitude de $8^{\circ} 32^{\prime} 26^{\prime}$ ' Sul, longitude de $37^{\circ} 41^{\prime}$ 25' Oeste com altitude média de $401 \mathrm{~m}$, na região semiárida do Estado de Pernambuco, Nordeste do Brasil. Anteriormente o município tinha a denominação de Mirim. Com a Lei Estadual n 4.956 de 20 de dezembro de 1963, foi desmembrado do município vizinho Inajá, sendo elevado à condição de município autônomo, com o nome de Ibimirim (CPRM, 2005; PMI, 2007; SALIN, 2010).

Segundo dados do IBGE, entre os anos de 2010 e 2017, este município tinha uma população de 26.954, com estimação de 28.985 habitantes para 2017, e um território de $1.906,437 \mathrm{~km}^{2}$. O município de Ibimirim tem uma densidade demográfica de 14,14 hab/Km² (IBGE, 2019). A cidade limita-se ao norte com os municípios de Sertânia e Custódia, ao sul com Inajá e Manari, a leste com Tupanatinga e a oeste com Floresta (SALIN, 2010; SANTOS, 2018). 
Figura 1: Localização do Município de Ibimirim, Estado de Pernambuco, República Federativa do Brasil.

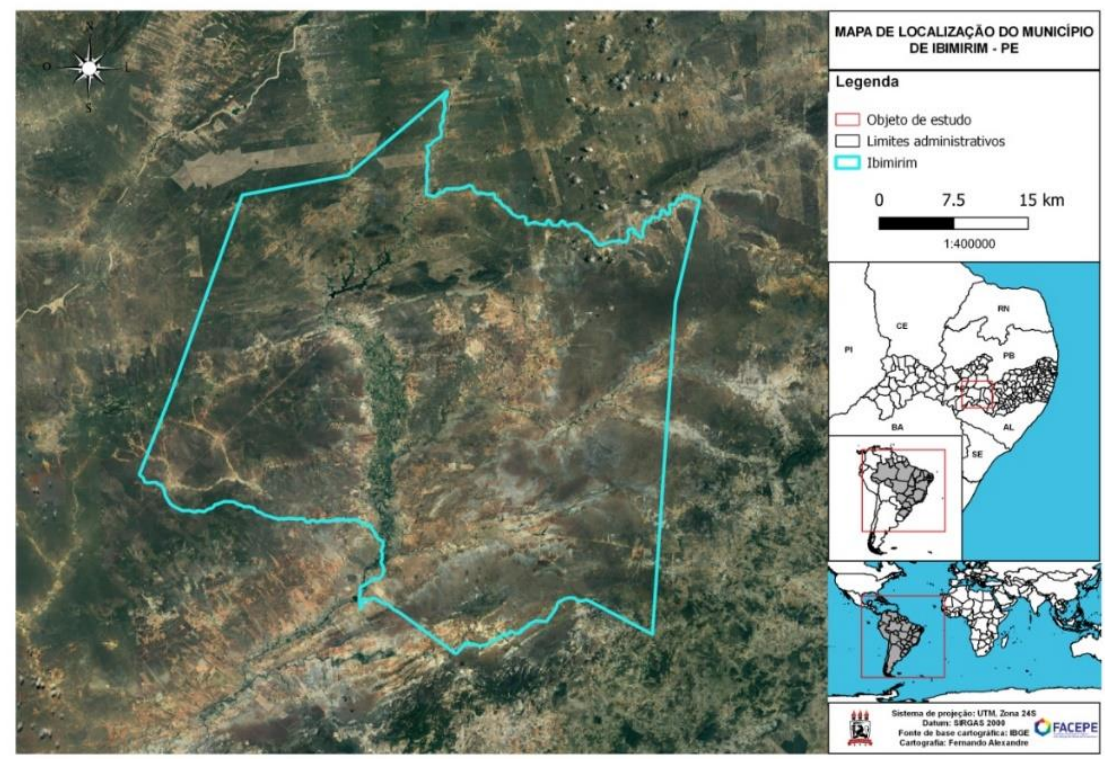

Fonte: Acervo do autor: SANTOS, P.R (2019).

O presente estudo, quanto à sua natureza e do ponto de vista de seus objetivos, é descritivo e exploratório (qualitativo) (PRODANOV; FREITAS, 2013, p. 52). Para alcançar os resultados almejados, o estudo faz uso de análise da literatura já existente - proposta por Bernardy (2013) e Mattos e Antoniazzi (2017) —, de apreciação documental e de observação, método empregado por Machado, Freire e Almeida (2016), a partir de estudos anteriores sobre a matéria Plano Diretor, em comento. De acordo com Gil (2008, p. 16), esse tipo de pesquisa consiste na observação ou apenas observa algo que acontece ou que aconteceu.

Neste contexto, a pesquisa foi dividida em três momentos distintos: i) pesquisa bibliográfica acerca dos temas estatuto da cidade, normas e legislações pertinentes; ii) análise documental do plano diretor participativo de Ibimirim; iii) campanhas de campo para identificação de ineficiências, através de registro fotográfico in loco. As investigações foram realizadas no intuito de observar a aplicabilidade dos instrumentos descritos no Plano Diretor do município durante o período de 2006 a 2018, bem como verificar as inconsistências, fragilidades e desafios existentes entre o que se encontra escrito e a prática executada pelo poder público municipal, no que tange aos instrumentos de regularização urbanística e ambiental.

\section{Resultados e discussão}

3.1 Plano diretor de Ibimirim - PE - marco histórico e estrutural

O Plano Diretor do Município de Ibimirim, criado pela Lei complementar nº 602/2007 
(PMI, 2007), tem suas origens em um plano regional que procurou subsidiar ações estratégicas, priorizadas pela sociedade civil e pelo poder público, na linha do desenvolvimento local, com ações no cenário do Programa de Combate à Pobreza Rural (PCPR) - Projeto Renascer. A partir deste momento, foi criada a tática de aglomerar 11 municípios de baixo Índice de Desenvolvimento Humano (IDH), inserindo as regiões do Agreste Meridional e do Moxotó (PMI, 2007).

A matriz de planejamento deste Plano Diretor Participativo foi desenvolvida em dez eixos temáticos: 01. Criança e Adolescente; 02. Políticas de Juventude; 03. Moradia; 04. Resíduos Sólidos; 05. Recursos Hídricos; 06. Estradas e Transporte; 07. Meio Ambiente; 08. Trabalho e Renda; 09. Segurança; 10. Gestão Municipal (PMI, 2007). O documento menciona com clareza que são objetivos específicos do Plano Diretor de Ibimirim:

\footnotetext{
Garantir a transparência da administração pública e a participação efetiva da sociedade civil organizada, a contribuir nas demandas do município. [...] Garantir a sua revisão a cada 2 (dois) anos, e/ou quando se fizer necessário, conforme demandas, se encontra em sua conjuntura das políticas públicas local/regional e ou nacional por ser um plano aberto às devidas proposições no que lhe confere a notificação quanto ao desenvolvimento do município e região (PMI, 2007, p. 1).
}

No que concerne à implantação do Plano Diretor no estado de Pernambuco, o órgão responsável por dar suporte técnico e financeiro ao processo de planejamento territorial aos municípios, inclusive ao de Ibimirim, é a Agência Estadual de Planejamento e Pesquisas de Pernambuco (AGÊNCIA CONDEPE/FIDEM, 2014).

3.2 Análises documentais - Quadro situacional e abordagens observacionais

O Plano Diretor Participativo de Ibimirim - cujas discussões e deliberações foram realizadas no ano de 2006 e que foi sancionado no ano posterior (2007), através da Lei complementar $\mathrm{n}^{\mathrm{o}} 602 / 2007$, conforme anteriormente explanado - , foi instituído para ordenar com responsabilidade todo o território municipal nas áreas urbanas e rurais, obedecendo com rigor às determinações constitucionais previstas nos artigos 182 e 183, e consequentemente, ao Estatuto das Cidades, Lei nº 10.257/2001 (BRASIL, 2001). Este instrumento foi instituído com o objetivo geral de coordenar ações da gestão pública municipal e o setor privado, dando ênfase às políticas nos âmbitos municipal, estadual e federal (PMI, 2007).

Para a elaboração do Plano Diretor, é necessário ouvir moradores das diferentes regiões da cidade e segmentos organizados da sociedade. A diversidade das visões sobre a cidade, construída pelos segmentos organizados, deve ser explicitada, trazendo para a esfera pública os 
interesses que embasam essas visões (FREITAS; BUENO 2018). O planejamento urbano é um processo de criação e desenvolvimento de programas que buscam melhorar a qualidade de vida da população (FILHO; OLIVEIRA, 2013).

Em análise efetuada ao documento do Plano Diretor Participativo de Ibimirim, constatou-se que, no eixo de resíduos sólidos, por exemplo, existem propostas diversas, como atividades de conscientização, redirecionamento dos resíduos sólidos para que não fiquem a céu aberto, integração entre os diversos setores para uma melhor gestão dos recursos, extensão da coleta para os distritos e sítios e incentivos para a reciclagem (PMI, 2007), porém, o plano não sugere quem serão os responsáveis por essas ações, nem as suas atribuições. Não existem ações focadas na mudança de hábitos e comportamentos (educação ambiental) da população de Ibimirim, em prol do gerenciamento hábil dos resíduos sólidos provenientes de diversas atividades, entre os quais os domésticos, comerciais e agrícolas.

Tal fato se explica pela falta de funcionamento das instalações do aterro sanitário construído desde o ano de 2012 (figura 2 a e d), para fins de tratamento apropriado dos resíduos produzidos pelo contingente populacional da zona urbana do município, conforme regramentos e normatizações estabelecidos pela Política Nacional de Resíduos Sólidos (PNRS) - Lei $12.305 / 2010$.

Segundo informes da prefeitura local, antes o convênio de parceria para descarte, gerenciamento e tratamento dos resíduos sólidos era efetivado entre os municípios de Ibimirim, Inajá e Manari. Atualmente (desde outubro de 2019), este convênio foi firmado entre as concessionárias dos municípios de Iguaracy, Custódia, Floresta e Inajá, inseridos nas proximidades do município de Ibimirim, para uma destinação apropriada dos resíduos e remediação dos lixões (figura 2 a, b, c, d).

A questão dos resíduos sólidos urbanos - RSU é amplamente discutida e a busca por soluções para a sua gestão adequada tem se constituído em um grande desafio para as administrações públicas. Desafio sobretudo no que concerne aos impactos socioambientais associados, bem como à compreensão e aperfeiçoamento dos mecanismos de coleta, transporte, tratamento, acondicionamento dos resíduos sólidos urbanos e destinação final ambientalmente adequada dos rejeitos (BARBOSA; JÚNIOR, 2020). É notório que falta em Ibimirim programas de coleta seletiva e reciclagem, focados na preservação do meio ambiente, geração de renda e bem-estar dos moradores e catadores de materiais recicláveis.

As figuras 2 a seguir nos mostram com exatidão o aterro sanitário e o lixão nos anos 2012 e 2018, que ficam a uma distância de aproximadamente $4 \mathrm{Kms}$ da zona urbana. Este último ocasiona intensos impactos ambientais à Bacia Hidrográfica do Moxotó e demais serviços 
ecossistêmicos, por poluição, contaminação do solo e dos recursos hídricos subterrâneos, devido, sobretudo, à produção escalar e sem tratamento adequado do líquido proveniente da matéria orgânica em decomposição, chamado chorume.

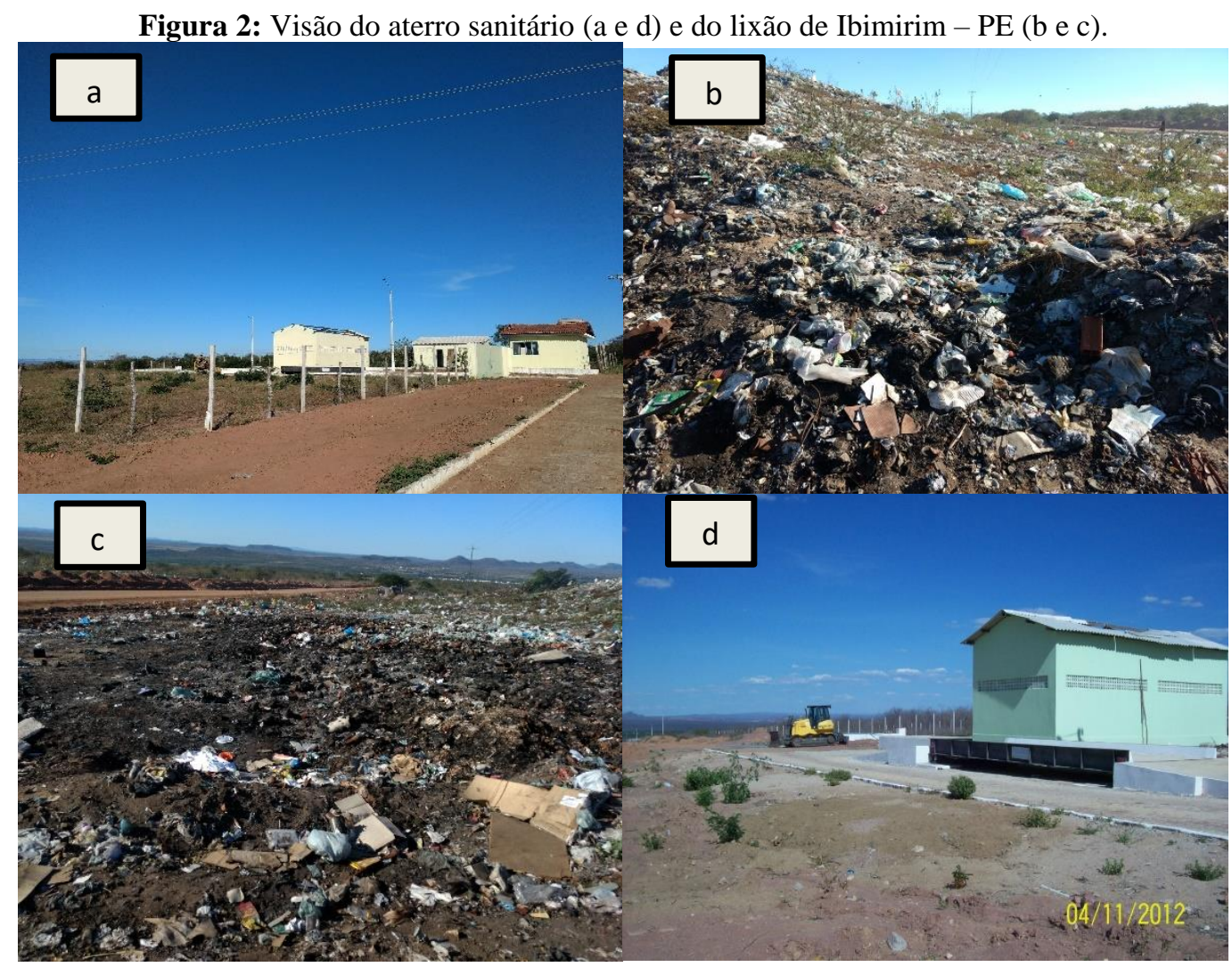

Fonte: Prefeitura Municipal de Ibimirim (2017) e acervo do autor: SANTOS, P. R (2018).

O eixo de recursos hídricos, no Plano Diretor de Ibimirim, apresenta propostas e os responsáveis pela execução das atividades. Observou-se que, apesar de várias instituições estarem no texto como responsáveis por atividades conjuntas - como é o caso da mobilização para o uso consciente da água e revitalização da mata ciliar —, não se verificou integração entre esses órgãos; logo, o eixo de recursos hídricos não tem execução concreta no município devido à falta de autonomia do município sobre eles.

Neste eixo foi possível verificar nascentes e margens do rio Moxotó, drenos e canais de irrigação invadidos pela espécie invasora algaroba (Prosopis juliflora) (S.W) D.C., ao invés de plantas nativas. Enquadra-se neste contexto o Açude Público Federal Engenheiro Francisco Sabóia, conhecido popularmente como Poço da Cruz, considerado o maior espelho d'água do estado de Pernambuco e que é responsável pelo abastecimento do distrito de Poço da Cruz e Perímetro Irrigado do Moxotó - PIMOX, gerando trabalho e renda para a região.

Além disso, percebeu-se durante as campanhas de campo uma significativa carência de 
serviços de saneamento básico no município, entre os quais se pode destacar com exatidão o despejo de efluentes domésticos in natura ou sem o devido tratamento prévio ao longo do Rio Moxotó (figura 3 a, b), que margeia a cidade. O Rio Moxotó, barrado ao longo do seu curso pelo reservatório do Poço da Cruz, é considerado um dos principais afluentes do rio São Francisco.

Figura 3: Vista de ponte sobre o rio Moxotó, de despejo in natura de esgoto doméstico, Bairro Lages, Ibimirim
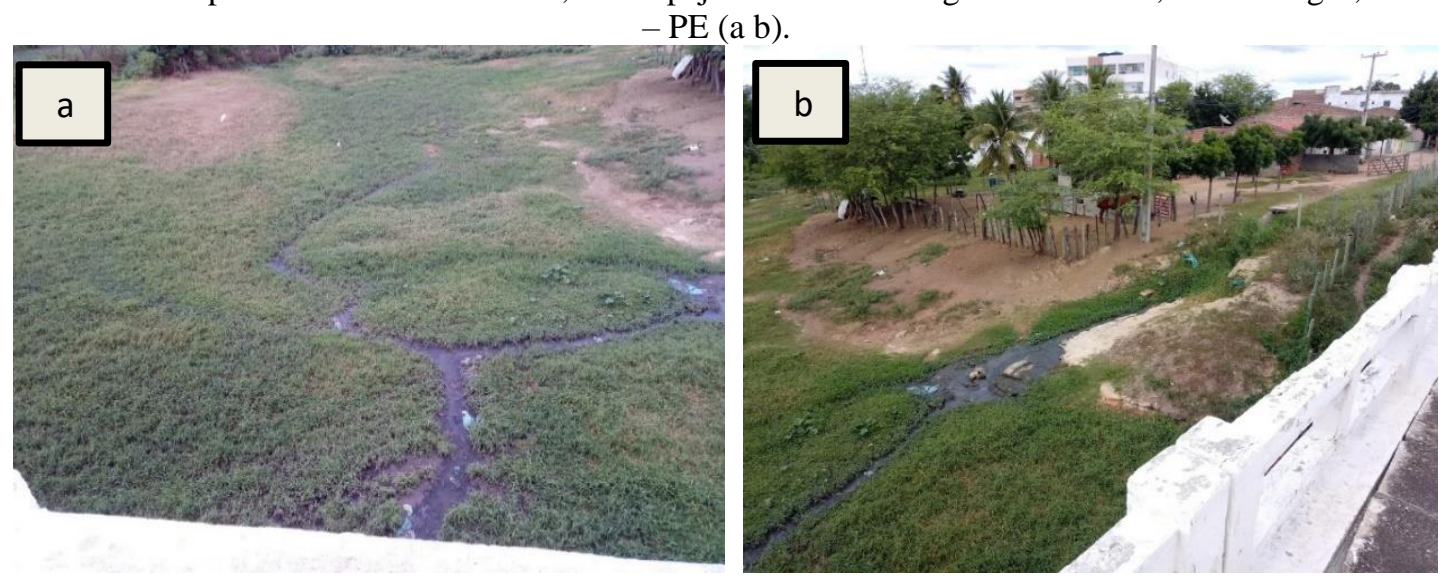

Fonte Acervo do autor: SANTOS, P.R. (2020).

De acordo com Pizella (2015), a atuação dos municípios como gestores dos recursos hídricos se efetiva por meio de sua participação nos Comitês de Bacias Hidrográficas, na medida em que compõem o Sistema Integrado de Gerenciamento de Recursos Hídricos (SIGRH). Contudo, apesar desta participação no Conselho Gestor de Águas - Consul e em outros institutos/instrumentos de gestão, ainda persistem as dificuldades e desafios já mencionados. Por ser os municípios o local onde as pessoas reproduzem sua cultura e por ser os impactos ambientais gerados pelo uso inadequado do solo, se configuram como importantes partícipes na gestão hídrica. Para Pizella (2015), os Planos Diretores Municipais devem inserir as diretrizes presentes nos Planos de Recursos Hídricos, com mecanismos de controle e fiscalização por parte dos cidadãos e da administração pública, que garantam seu cumprimento.

O eixo de meio ambiente está composto por: vegetação, solo, clima, urbanismo, paisagismo, reflorestamento, desmatamento, manejo da vegetação, zoneamento ecológico e aptidões de solo, caça e pesca, regularização do uso de agrotóxicos e fertilizantes químicos (PMI, 2007). Esse é o eixo que possui o maior número de parcerias, mas também é um dos mais difíceis de ser postos em prática. Primeiro, porque envolve vários interesses, principalmente econômicos. Para Marcello, Teveira e Crotti (2016), a urbanização é um dos processos que mais impacto produz sobre o meio ambiente, o que torna imprescindível o controle e planejamento da expansão urbana por parte dos gestores públicos que visam o desenvolvimento das cidades. 
Técnicas hábeis - com foco na restauração e recuperação áreas degradadas, manejo, e qualidade da água - como o reflorestamento e tratamento de esgoto respectivamente, exigem tempo para alcançar um equilíbrio em virtude da ineficiência na implementação de políticas públicas voltadas para este fim. Além disso, existe falta de conhecimento de muitas pessoas que degradam os recursos da natureza, entre eles os próprios agricultores do Perímetro Irrigado do Moxotó - PIMOX. O uso inapropriado de fertilizantes e agrotóxicos, a excessiva utilização das águas em virtude da adoção do sistema de irrigação por sulcos desencadeia empobrecimento dos solos pelo processo de salinização, entre outros agravos. Eles o fazem sem a mínima consciência das possíveis implicações sobre os recursos naturais.

Dentro do eixo de meio ambiente, criança e adolescente, se destaca no município o Centro de Educação Ambiental do Semiárido de Pernambuco - CEASAPE, regido pela ONG Associação Umburanas do Vale do Moxotó - ASSUVAM, que atua na região do Moxotó desde o ano 2002 com o objetivo de promover o desenvolvimento sustentável da terra e sensibilizar às crianças, adolescentes e jovens acerca da questão ambiental (CEASAPE, 2012). No CEASAPE, verificou-se a utilização de placas solares na geração de energia para bombeamento de água de poços artesianos; aproveitamento de gorduras vegetais e animais para produção de sabão; artesanato como forma de reaproveitamento da madeira proveniente da poda das árvores da cidade (marchetaria); entre outras medidas de respeito pelo ambiente. Um dos principais objetivos da Associação Umburanas é a educação ambiental e a inclusão social da população do município e região (SOUZA, 2009; SANTOS et al., 2018; SANTOS et al., 2019).

O Serviço de Tecnologia Alternativa - Serta desempenha atividades de cunho agroecológico e extensão como Organização da Sociedade Civil de Interesse Público (OSCIP). Tem como missão formar jovens, educadores/as e produtores/as familiares, para atuarem na transformação das circunstâncias econômicas, sociais, ambientais, culturais e políticas, na promoção do desenvolvimento sustentável, com foco no campo (SERTA, 2019). No entanto, existem algumas fragilidades que precisam serem preenchidas com relação ao trabalho executado pelas instituições anteriormente mencionadas como, por exemplo, a escassa divulgação, valorização e apoio da administração pública nas esferas federal, estadual e local. De acordo com Bernardy (2013):

Os aspectos socioespaciais dos munícipes são fortemente influenciados pela capacidade que os atores locais possuem em criar pactos entre os diferentes segmentos representativos, como o poder Executivo municipal, as entidades representativas da sociedade civil, as Organizações Não Governamentais e os próprios cidadãos de forma coletiva ou individualizada (BERNARDY, 2013, p. 1). 
O Plano Diretor de Ibimirim (2007) estabelece como diretriz do eixo moradia: normatizar a política de arquitetura urbana e rural da lei de uso do solo; garantir o cumprimento da legislação de pessoas com deficiência; melhorar as condições das moradias de baixa renda. No que tange ao cenário, proposições e diretrizes, o referido documento propõe a implantação de lei de regularização do uso do solo, de um código de ética e a implantação de uma política estrutural arquitetônica a fim de corrigir e reestruturar a cidade, de forma humanizada e prazerosa (PMI, 2007). Porém, percebe-se que estas normatizações e realizações na prática não existem.

Constatou-se que o município não possui Código de Obras e Edificações, instrumento de controle e fiscalização do espaço construído, nem um código de posturas. Conforme podemos observar na figura (3 a, b), há residências construídas fora dos parâmetros estabelecidos por lei, em especial a NBR 5090\2015, que disciplina acerca da acessibilidade a edificações, mobiliário, espaços e equipamentos urbanos, bem como determina as dimensões mínimas das calçadas: faixa de serviço, faixa livre ou passeio e faixa de acesso.

Figura 4: Fachada de residência ocupando a calçada (a) e calçada fora do dimensionamento mínimo exigido por lei em Ibimirim - PE (b).



Fonte: Acervo do autor: SANTOS, P.R. (2017).

Segundo explanações de representantes da gestão pública municipal, os códigos se encontram em processo de construção, juntamente com a renovação do plano diretor participativo o qual, desde o seu planejamento e elaboração no ano 2006, não passou por revisões (PMI, 2007; PMI, 2017). O Estatuto das Cidades, Lei 10.257/2001, estabelece no seu cap. III - Do plano diretor, art. 40 - que o plano diretor, aprovado por lei municipal, é o instrumento básico da política de desenvolvimento e expansão urbana; o parágrafo 3 reforça que a lei que instituir o plano diretor deverá ser revista, pelo menos, a cada dez anos (BRASIL, 
2001).

Desse modo, Bernardy (2013) relata que

\begin{abstract}
Nos pequenos municípios, entre os mecanismos legais mais difundidos está a Lei Orgânica Municipal, que comumente versa de forma muito simplificada e superficial sobre o planejamento urbano e municipal. Em uma segunda escala seria fundamental que os pequenos municípios tivessem um plano diretor, uma vez que permitiria a existência de uma série de leis complementares e vinculadas, como o código de posturas, de edificações, do sistema viário, do meio ambiente e outros (BERNARDY, 2013, p. 5).
\end{abstract}

O referido Estatuto da Cidade, no seu art. 41, expõe que o Plano Diretor é obrigatório para as seguintes cidades:

\footnotetext{
I - Com mais de vinte mil habitantes;

II - Integrantes de regiões metropolitanas e aglomerações urbanas;

III - onde o Poder Público municipal pretenda utilizar os instrumentos previstos no $\S$ $4^{\circ}$ do art. 182 da Constituição Federal;

IV - Integrantes de áreas de especial interesse turístico;

$\mathrm{V}$ - Inseridas na área de influência de empreendimentos ou atividades com significativo impacto ambiental de âmbito regional ou nacional;

VI - Incluídas no cadastro nacional de Municípios com áreas suscetíveis à ocorrência de deslizamentos de grande impacto, inundações bruscas ou processos geológicos ou hidrológicos correlatos (BRASIL, 2001).
}

O Plano Diretor é essencial para o uso adequado do solo no município, em especial a previsão de crescimento urbano vertical ou horizontal, o desenvolvimento econômico, as redes de infraestrutura e de serviços públicos, as limitações urbanísticas para as edificações, a preservação ambiental, a habitação de interesse social, a regularização fundiária e a gestão democrática e participativa (BERNARDY, 2013).

Não há um zoneamento do espaço urbano-ambiental descrito no documento do Plano Diretor do município de Ibimirim. O zoneamento neste contexto se trata da separação da cidade e extensões campesinas em zonas específicas, recintos de indústria, de mobiliários, de moradias, ambientes agropecuários, protegidos e turísticos, etc. Segundo Marcello, Teveira e Crotti (2016), o zoneamento é um instrumento para realizar a parte do Plano Diretor que se refere à regularização do uso do solo, delimitando geograficamente áreas territoriais, com o objetivo de estabelecer regimes especiais de uso, gozo e fruição da propriedade, sob a tutela do permitido e do proibido.

\title{
4 Conclusão
}

Com a realização desta pesquisa, deixou-se claro que não existe fiscalização no que concerne à aplicação da Lei 10.257/2001, do Estatuto da Cidade, em especial em relação ao 
Plano Diretor e ao uso e ocupação do solo no município de Ibimirim - PE. A Lei 10.257/2001 2001 (Estatuto da Cidade) está prevista para ser cumprida conforme determinações estabelecidas, mas a inexistência de aplicação e implantação dos planos diretores esbarra na falta de estrutura e compromisso político nas diversas esferas do poder público, não somente municipal, mas também estadual e federal. É preciso mais organização e divulgação entre os habitantes da cidade para que se formulem ideias dirigidas à criação de uma sociedade mais justa e com melhores condições de vida para as presentes e futuras gerações.

Faz-se necessário definir linhas para o planejamento da cidade (povoados, bairros, vilas, ruas, etc.), apresentar diretrizes e mecanismos para o seu crescimento ordenado, para a preservação do meio ambiente, a melhoria da qualidade da infraestrutura e a qualidade de vida da população, através de investimentos em serviços como: saneamento ambiental; arborização urbana, reflorestamento e compensação nas margens e nascentes dos rios, com espécies nativas; saúde; educação; transporte coletivo; fiscalização urbana e ambiental; e ainda equipamentos urbanos para que o Plano Diretor da cidade de Ibimirim - PE seja de fato eficiente.

Esta pesquisa possibilitará criar consciência nos poderes públicos municipais do semiárido brasileiro, em prol da renovação e implantação dos planos diretores participativos, pois com este estudo se pode constatar que grande parte da população ainda não tem conhecimento desse documento e por isso acaba não contribuindo para a sua efetivação.

\section{Agradecimentos}

À Universidade Norte do Paraná - UNOPAR pelo título, conhecimentos e ensinamentos proporcionados durante o curso de especialização Lato Sensu em Gestão, Licenciamento e Auditoria Ambiental (2016-2017) e à Fundação de Amparo à Ciência e Tecnologia do Estado de Pernambuco - FACEPE, pela bolsa de estudo concedida ao primeiro autor junto ao Programa Regional de Pós-Graduação em Desenvolvimento e Meio Ambiente (PRODEMA/UFPE) durante o Biênio 2019/2021.

\section{Referências}

AGÊNCIA CONDEPE/FIDEM. Experiência de planos diretores participativos em

Pernambuco. Disponível em: http://www2.condepefidem.pe.gov.br/web/condepe-fidem/aexperiencia-de-planos-diretores-participativos. Acesso em: 26 fev. 2020.

ASSOCIAÇÃO BRASILEIRA DE NORMAS TÉCNICAS (ABNT). NBR 9050: Acessibilidade a edificações, mobiliário, espaços e equipamentos urbanos. 2004. Rio de Janeiro: ABNT, 2004. 
BARBOSA, R. G. Planejamento urbano e segregação socioespacial na cidade de Macapá. Revista Eletrônica de Humanidades do Curso de Ciências Sociais da UNIVAP PRACS, Macapá, n. 6, p. 135-148, dez. 2013.

BARBOSA, L. N. V.; JÚNIOR, F. H. C. Estudo de indicadores para a gestão de resíduos sólidos urbanos no município de Maracanaú - Ceará. Revista Meio Ambiente e Sustentabilidade, Curitiba, v. 9, n. 18, jan./jun. 2020.

BERNARDY, R. J. O plano diretor como instrumento essencial para o desenvolvimento urbano de pequenos municípios. In: SEMINÁRIO NACIONAL SOBRE

DESENVOLVIMENTO REGIONAL. CRISES DO CAPITALISMO, ESTADO E DESENVOLVIMENTO REGIONAL, 6., 2013, Santa Cruz do Sul, RS, Brasil. Anais [...]. Santa Cruz do Sul: UNISC, 2013.

BRASIL. Lei $\mathbf{n}^{\mathbf{0}}$ 10257, de 10 de julho de 2001. Estatuto das Cidades - Regulamenta os arts. 182 e 183 da Constituição Federal, estabelece diretrizes gerais da política urbana e dá outras providências. Brasília: Presidência da República; Casa Civil, 2001. Disponível em: http://www.planalto.gov.br/ccivil_03/leis/LEIS_2001/L10257.htm. Acesso em: 26 de fev. 2020.

CPRM. Projeto Cadastro de fontes de abastecimento de água subterrânea. Diagnóstico do município de Ibimirim, estado de Pernambuco. Recife: CPRM/PRODEEM, 2005.

\section{CEASAPE - CENTRO DE EDUCAÇÃO AMBIENTAL NO SEMIÁRIDO}

PERNAMBUCANO (Ibimirim). Ceasape - Centro de Educação Ambiental no Semiárido Pernambucano. Projeto Minha Cidade, Minha Imagem. Ibimirim: Ceasape, 2012.

FARIAS, E. V. S., SILVA, E.V., RODRIGUEZ, J. M. M. Aspectos do uso e ocupação do solo no semiárido cearense: análise espaço temporal (1985 - 2011) sob o viés da geoecologia das paisagens. Revista Brasileira de Geografia Física, Recife. v. 6, n. 2, p. 136-147, 2013.

FILHO, R. S. J., OLIVEIRA, T. S. M. Planejamento e sustentabilidade urbana. Caderno Organização Sistêmica, Curitiba, v. 3, n. 2, jul./dez, 2013.

FREITAS, E. L. H.; BUENO, L. M. M. Processos participativos para elaboração de Planos Diretores Municipais: inovações em experiências recentes. Urbe. Revista Brasileira de Gestão Urbana, Curitiba, v. 10, n. 2, p. 304-321, maio/ago. 2018.

GIL, Antônio Carlos. Como elaborar projetos de pesquisa. 4. ed. São Paulo: Atlas, 2008.

INSTITUTO BRASILEIRO DE GEOGRÁFIA E ESTATÍSTICA - IBGE. Panorama de Ibimirim. 2017. Disponível em: https://cidades.ibge.gov.br/brasil/pe/ibimirim/panorama. Acesso em: 03 de dez. 2017.

INSTITUTO BRASILEIRO DE GEOGRÁFIA E ESTATÍSTICA - IBGE. Panorama de Ibimirim. 2019. Disponível em: https://cidades.ibge.gov.br/brasil/pe/ibimirim/panorama. Acesso em: 23 de ago. 2019. 
MACHADO, E. G.; FREIRE, G. M. C.A; ALMEIDA, A. P. Extensão universitária, planejamento urbano e democracia na elaboração de um plano diretor participativo no semiárido nordestino. Rev. Ciênc. Ext., São Paulo, v. 12, n. 1, p. 63-79, 2016.

MARCELLO, T.; TEVEIRA, A. V. A.; CROTTI, P. C. Zoneamento municipal como instrumento regularizador do uso e ocupação do solo: Uma análise da legislação municipal de São Francisco Beltrão. Gestão e Desenvolvimento em Revista, Francisco Beltrão PR, v. 2, n. 1, p. 41-55., jan./jun. 2016.

MATTOS, C. M.; ANTONIAZZI, M. T. H. Gestão pública: o plano diretor e sua importância no processo de desenvolvimento sustentável municipal. Caderno Gestão Pública, Curitiba, v. 8, n. 5, 2016. Disponível

em: https://www.uninter.com/cadernosuninter/index.php/gestaopublica/article/view/514/463. Acesso: em 26 fev. 2020.

MEURIER, F.; VIEIRA, G. F. Plano diretor para municípios pequeno porte: a experiência do plano diretor regional participativo da Amavi. In: SEMINÁRIO POLÍTICA E PLANEJAMENTO, 2., 2010, Curitiba. Anais [...]. Curitiba: Ambiens, 2010.

OLIVEIRA, Celso Maran de; LOPES, Dulce; SOUSA, Isabel Cristina Nunes de. Direito à participação nas políticas urbanísticas: avanços após 15 anos de estatuto da cidade. Urbe, Rev. Bras. Gest. Urbana, Curitiba, v. 10, n. 2, p. 322-334, ago. 2018. Disponível em: http://www.scielo.br/scielo.php?script=sci_arttext\&pid=S2175$33692018000200322 \& \operatorname{lng}=$ en\&nrm=iso. Aceso em 26 fev. 2020. DOI: https://doi.org/10.1590/2175-3369.010.002.ao04.

PIZELLA, D.G. A relação entre Planos Diretores Municipais e Planos de Bacias Hidrográficas na gestão hídrica. Rev. Ambient. Água, Taubaté, v. 10, n. 3, jul./set. 2015. DOI: $10.4136 / 1980-993 X$.

PMI - PREFEITURA MUNICIPAL DE IBIMIRIM. Lei complementar 602/2007, de 27 fevereiro 2007. Ementa. Cria e disciplina o Plano Diretor do Município Ibimirim de Pernambuco. Ibimirim: PMI, 2007. Disponível em: https://ibimirim.pe.gov.br/wpcontent/uploads/2020/06/Lei-603-2007.pdf. Acesso em: 01 mar. 2020.

PMI - PREFEITURA MUNICIPAL DE IBIMIRIM. Pmi, 2017, 2019, 2020. Disponível em: https://ibimirim.pe.gov.br/. Acesso em: 01 mar. 2020.

PRODANOV, C.C.; FREITAS. E.C. Metodologia do trabalho científico: Métodos e técnicas da pesquisa e do trabalho acadêmico. 2. ed. Novo Hamburgo RS: Universidade Feevale, 2013.

SALIN, T. C. Caracterização de sistemas de produção no município de Ibimirim, região semiárida de Pernambuco: as bases para um planejamento agroflorestal. 2010. $124 \mathrm{f}$. Dissertação (Mestrado em Ciências Florestais) - Departamento de Ciência Florestal, Universidade Federal Rural de Pernambuco, Recife, 2010.

SANTOS, P. R.; VASCONCELOS, G. S.; LIMA, B. L. C.; OLIVEIRA, D. A. S.; FELINTO, A. C.; SANTOS, C. G. ONG na produção de mudas no semiárido de Pernambuco: uma busca 
pela recuperação ambiental. Revista Ambientale, Maceió, v. 10, n. 3, out./dez., p. 61-71, 2018.

SANTOS, P. R.; CAVALCANTI, M. L.C.; SANTOS, L., C.; COSTA, A. M. M. Fabricação de artefatos a partir do aproveitamento de biomassa residual no semiárido de Pernambuco. In: CONGRESSO BRASILEIRO DE GESTÃO AMBIENTAL, 10., 2019, Fortaleza. Anais [...]. Fortaleza, UNIFOR, 2019. Disponível em:

http://www.ibeas.org.br/congresso/Trabalhos2019/III-135.pdf. Acesso em: 29 ago. 2020.

SANTOS, T. C. G. Avaliação de impactos, vulnerabilidades e estratégias de adaptação às mudanças climáticas no semiárido pernambucano: estudo de caso do APL de agricultura familiar no Perímetro Irrigado do Moxotó - PIMOX, Sertão do Moxotó (Ibimirim - PE). 2018. 80 f. Dissertação (Mestrado em Engenharia Ambiental) - Pró-reitoria de Pesquisa e Pós-Graduação, Universidade Federal Rural de Pernambuco, Recife, 2018.

SERTA - SERVIÇO DE TECNOLOGIA ALTERNATIVA. Sobre. 2019. Disponível em: http://www.serta.org.br/sobre/. Acesso em: 01 mar. 2020.

SOUZA, E. G. F. Os paradigmas da agricultura convencional e agroecológica no município de Ibimirim - PE. 2009. In: JORNADA DE ENSINO, PESQUISA E EXTENSÃO JEPEX, 9., 2009, Recife. Anais [...]. Recife: Universidade Federal Rural de Pernambuco UFRPE, 2009. 